\title{
Epoxy Resin for Sealing the Underground Hydrogen Storage Reservoirs
}

\author{
Dawid Gajda \\ Silesian University of Technology, \\ Faculty of Mining, Safety Engineering and Industrial Automation \\ ul. Akademcka 2, 44-100 Gliwice, Poland \\ dawid.gajda@polsl.pl
}

\begin{abstract}
To increase the renewable energy production, it is necessary to provide large-scale energy storage to reduce the fluctuations from wind and solar plants. One of the possibility is to store hydrogen from electrolysis in underground mine excavations. Hydrogen can be stored as a blend with methane. Concept is promising especially in the coalfields, where a lot of underground excavations will be available in the future due to the reducing the coal production and closure of underground coal mines. Promising type of excavations are shafts, because of the geomechanical stability, presence of concrete or bricked lining, accessibility and presence of surface buildings. To adapt the underground excavation into hydrogen/methane storage facility, the surface of the excavation need to be sealed to prevent the hydrogen from leaking. Epoxy resins are selected as a material for the sealing liner. In this paper, a certain commercial epoxy resin with different admixtures was investigated for hydrogen permeability. Obtained permeability is $1,8 * 10^{-11}$ to $3,1 * 10^{-11} \mathrm{~cm}^{3} \mathrm{STP} * \mathrm{~cm}^{*} \mathrm{~cm}^{-2} * \mathrm{~s}^{-1} * \mathrm{cmHg}^{-1}(0,18$ to 0,31 barrer). Hydrogen permeability of salt rock and stainless steel was also presented to compare with the epoxy resin. Thanks to the liquid form during pot time, epoxy resin is able to fill the voids in the existing shaft lining, providing the additional reinforcement of the construction. After pot time, it achieves chemical, mechanical and temperature resistance, as well as satisfying sealing properties. All these properties are making the epoxy resin a promising lining material for hydrogen storage in adapted underground excavations.
\end{abstract}

Keywords: epoxy resin hydrogen permeability, hydrogen diffusion, hydrogen storage

\section{Introduction}

Energy storage is necessary to balance the fluctuations in energy production in wind and solar farms. Excess energy in peak production can be temporary stored and utilized in peak demand periods. For a country - scale energy demands, only underground energy storage is capable enough to provide the proper amount of buffer energy [1]. Hydrogen is considered as the energy carrier, which is easy to obtain in electrolysis, powered with the excess energy. Although hydrogen is difficult to store because of the high capability to diffuse, causing the leaks, as well as steel embrittlement [2]. One of the possibility is storing hydrogen (in different forms) in salt caverns. It is possible due to the good sealing properties of the salt rock. There are known natural gas storage sites in salt caverns across the Europe. But they are limited by the presence of suitable salt formations. Salt cavern gas storage also meets some problems with the stability of the caverns.

One of the concept solution for hydrogen/methane blends storage is adapting the underground mine excavations in abandoned underground mines. There are known cases of adapting the abandoned underground coal mines into the natural gas storage facilities in Leyden, Colorado and Perrones, Belgium, with the first one still operating [3]. There are also a few known Lined Rock Cavern objects for storing natural gas in Sweden and Japan [4,5]. Combining both solutions can make the possibility to store hydrogen as the energy buffer beyond the salt formation regions and at the same time utilize the existing mine infrastructure, which would partly solve the reclamation problem of the underground mines in closure process. Another advantage is possibility to utilize the methane from the abandoned coal mine. Long after mine closure, there may still be necessity to capture the methane from residue deposits.

\section{General Concept and the Lining Materials}

To reduce the invest costs, that concept is putting emphasis on adapting the existing underground excavations. Nevertheless, drilling down dedicated excavations is also possible, but will impact the economy of the concept 
significantly. The most suitable mine excavations for adaptation into gas storage reservoir seem to be the shafts. Because of the round cross section and vertical orientation, shaft is the most stable underground excavation. Another advantages is the accessibility, including the coexisting shaft buildings on the surface. Shafts also have existing lining, usually made from bricks or concrete. Shaft lining is giving a reinforcement and general stability, but during adaptation for hydrogen storage, the surface need to be additionally lined with impermeable material to prevent the hydrogen from leaking and diffusing. Recent research shows, that concrete do not have a proper sealing properties. Because of the multi grain structure, even additives can only reduce the gas permeability of concrete, but not make the concrete impermeable, especially for hydrogen [6].

Concept of adapting mine excavation into underground hydrogen storage facility is based on the 3 main aspects:

- technical infrastructure, including pipelines, valves, compressors etc.,

- geotechnical and geomechanical aspects, including stability of the excavation/gas depot, rock mass and gas pressure influence, plugs and general construction,

- proper sealing of the excavation/reservoir surface to prevent hydrogen from leaking.

Technical infrastructure can be adapted from the existing hydrogen/methane storage sites in salt caverns. This concept do not require any special equipment other that the one utilized in the hydrogen storage. Only hydrogen embrittlement of steel must be taken into account. The geotechnical aspects are also known from long-term observations of the shafts behaviour. A lot of experience in gas storage behaviour, especially during filling/emptying process was also gained [3,5]. This paper will focus on the third challenge related with selecting proper sealing liner.

Basing on the literature data and recent research, a polymer materials, in particular resins, were selected for sealing the excavation surface. Polymers are materials consist of subunits, which by theirs repeatability, make a long chains. They are made in the process of polymerisation - combining small molecules into a chain or network. Polymers can be synthetic, as well as natural, including biopolymers. Epoxy resins considered in this paper, consist of bisphenol with epichlorohydrin. In general, polymer materials are divided into 3 main groups, differing in structure, which leads to the differences in the properties as well [7]:

- thermoplastics - with linear structure, malleable after exposing to heat,

- thermosets - with cross-linked structure, resistant to heat and mechanical stress,

- elastomers - with light cross-linked structure, elastic and stretchy, but recover their original shape after removing stress.

For the sealing purpose, the best performance will be given with the thermosets. First of all, thermosets has a solid structure with high impact, chemical and temperature resistance. Thermosets during the pot time are a viscous liquid, which is capable to fill any voids in the base structure. This polymer group also has a strong adhesive properties, which gives extra reinforcement of the whole surface. Thanks to the much lower density than a stainless steel, the resin lining will not overload the general construction. Another very useful property is the highest gas impermeability of the thermosets, comparing to the other polymer groups. These properties are making the thermosets one of the best material for the sealing properties.

\section{Research methodology \\ 3.1. Samples preparation}

Investigated samples were made, using commercial epoxy resin from Polish manufacturer, consists of bisphenol with epichlorohydrin, with high epoxide number. A few different samples were made: pure epoxy, epoxy with amorphous graphite and epoxy with grinded halloysite. Components of resin were precisely mixed, than poured into 1-inch tubes, receiving the cylinder - shape samples of 1 inch $(25 \mathrm{~mm}$ ) diameter and approx.. $30 \mathrm{~mm}$ tall. Admixtures (amorphous graphite $<50 \mu \mathrm{m}$, halloysite $<125 \mu \mathrm{m}$ ) were added into the liquid resin in amount of $5 \%$ of volume. Samples were stored at $40^{\circ} \mathrm{C}$ during the pot time (time when the resin remains liquid). For comparison, a sample of salt rock from Polish salt mine of Permian - Zechstein age dome deposit was investigated. 


\subsection{Hydrogen permeability}

Hydrogen permeability test was performed on setup shown in the figure 1, which was designed and built in Unconventional Gas and CO2 Storage Laboratory at the Silesian University of Technology. Permeability test is based on the Carrier Gas Method. Sample is hold in PVC sleeve with confining pressure of water. Confining pressure is twice higher than feed gas pressure. Mixture of $10 \%$ of hydrogen in methane is put on the feed side (upstream side) of the sample with 10 bars $(1 \mathrm{MPa})$ relative pressure. Precise pressure measurements are helping to keep the steady conditions during research. However, hydrogen permeability is too small to be detected by the pressure changes. The actual amount of hydrogen on the permeate side (downstream side) was measured, using single gas - hydrogen detector with sensitivity of 2-2000 ppm. Knowing the volume of the permeate side of the setup, the mole volume and number of elements of diffused hydrogen is possible to be calculated, basing on the measured concentration of hydrogen in downstream side. Helium was used as a carrier gas (sweep gas) with relative pressure of 1 bar $(0,1 \mathrm{MPa})$ on the permeate side. Measurements were performed in 2-3 days intervals. After each measurement, the permeate side was vacuumed and filled with helium.

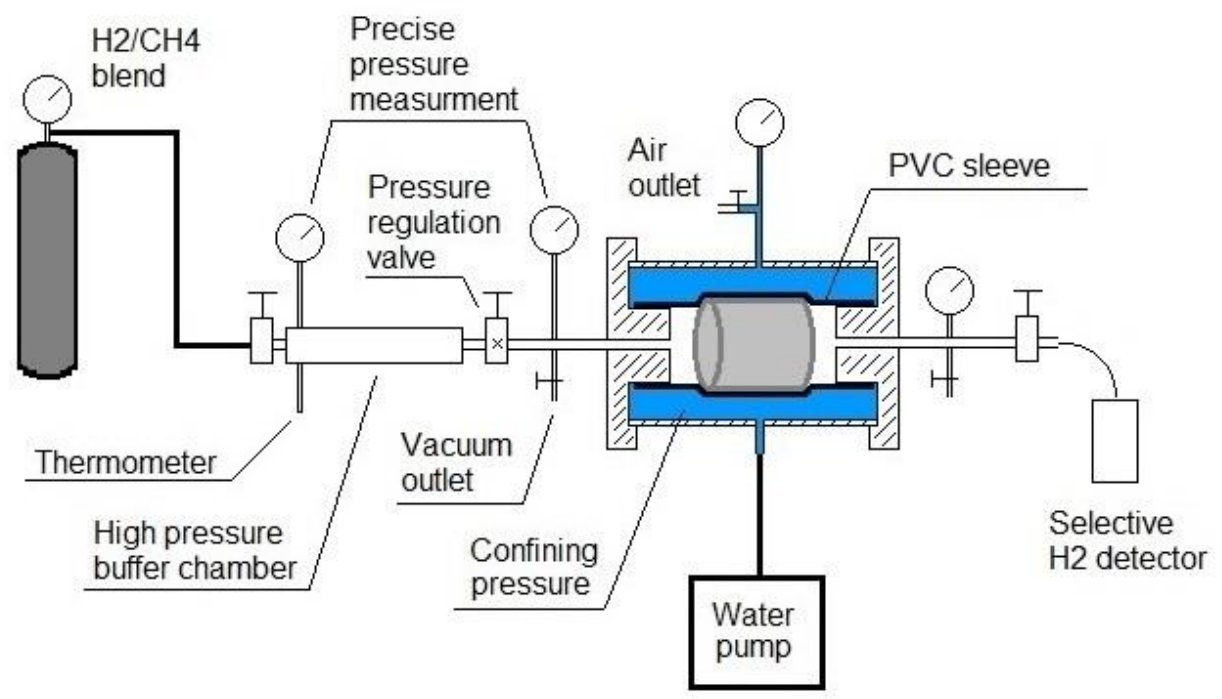

Fig. 1: Setup for Carrier Gas Method used for the hydrogen diffusion test.

Test was continued until achieving the steady state diffusion (concentration of hydrogen in measure intervals became stable). Usually it took up to 3 weeks. Calculations were made assuming that the sweep gas is an ideal gas. According to the ideal gas law, molar volume (volume of one mole) of ideal gas $\left(\mathrm{V}, \mathrm{m}^{3}\right)$ in certain temperature $(\mathrm{T}, \mathrm{K})$ and sweep gas pressure ( $\mathrm{p}, \mathrm{Pa})$ can be calculated (1), where $\mathrm{R}$ is the universal gas constant $\left(8,314463 \mathrm{~J}^{*} \mathrm{~mol}^{-1 *} \mathrm{~K}^{-1}\right)$. Volume of 1 mole of gas at standard temperature and pressure (STP) is also calculated, which gives 22,414 litres $\left(22414 \mathrm{~cm}^{3}\right)$.

$$
V=\frac{R * T}{p}
$$

Measured concentration of hydrogen (c, ppm) after achieving steady state, was related with the calculated molar volume of sweep gas $\left(\mathrm{V}, \mathrm{m}^{3}\right)$ and volume of downstream side of the setup ( $\mathrm{v}_{\text {downstream }}, \mathrm{m}^{3}, 12,0 \mathrm{~cm}^{3}$ in described setup), giving the actual amount of hydrogen elements $\left(\mathrm{N}_{\mathrm{H} 2}\right)$ diffused through the resin sample in certain time (2), where $\mathrm{N}_{\mathrm{A}}$ is the Avogadro constant $\left(6,02214076 * 1023 \mathrm{~mol}^{-1}\right)$.

$$
N_{H_{2}}=\frac{c *\left(\frac{N_{A}}{V}\right) v_{\text {downstream }}}{10^{6}}
$$


Number of hydrogen elements that had diffused through the sample can be transformed into volume of hydrogen in $\mathrm{STP}$, given in cubic centimetres $\left(\mathrm{V}_{\mathrm{H} 2}, \mathrm{~cm}^{3} \mathrm{STP}\right)$, using equation (3), where 22414 is the molar volume of gas at STP $\left(273,15 \mathrm{~K}, 10^{5} \mathrm{~Pa}\right)$ given in $\mathrm{cm}^{3}$.

$$
V_{H_{2}}=\frac{N_{H_{2}} 22414}{N_{A}}
$$

Using the equation (4), hydrogen permeability coefficient $\left(\mathrm{P}_{\mathrm{H} 2}\right)$ of sample was calculated. Measured concentrations of hydrogen was related with a time of exposure (t), gas pressure (p) and known dimensions of the sample (1 - length, A cross section area). Unit used to present the gas permeability is barrer [8], shown in equation (5). It is a non SI unit, but is commonly used in literature and easy - comparable with different materials. Barrer unit also enables to estimate the amount of gas, which will permeate at a certain storage conditions (time, pressure, lining thickness, surface area and permeability coefficient). Barrer equation is using a cmHg pressure unit, which need to be transformed from bar ( $1 \mathrm{bar} \Leftrightarrow$ $75,02 \mathrm{cmHg})$. However, received value of diffused hydrogen, given in cubic centimetres STP $\left(\mathrm{cm}^{3} \mathrm{STP}\right)$ is used in the equation directly.

$$
P_{H_{2}}=\frac{V_{H_{2}} l}{A * t * p}
$$

$$
\text { 1barrer }=\frac{\mathrm{cm}_{\mathrm{STP}}^{3} * \mathrm{~cm}}{\mathrm{~cm}^{2} * S * \mathrm{cmHg}} * 10^{-10}
$$

Estimating the hydrogen loss $\left(\mathrm{V}_{\mathrm{H} 2}, \mathrm{~cm}^{3} \mathrm{STP}\right)$ in a model storage is possible, using the transformed barrer equation (6). Known factors: inner surface area of the gas tank $\left(\mathrm{A}, \mathrm{cm}^{3}\right)$, pressure (p, bar $\left.\Leftrightarrow \mathrm{cmHg}\right)$, thickness $(1, \mathrm{~cm})$ and gas permeability coefficient of the liner $\left(\mathrm{P}_{\mathrm{H} 2}\right.$, calculated with equation (4)), can be used to estimate the amount of hydrogen loss by the diffusion through the epoxy resin sealing liner.

$$
V_{H_{2}}=\frac{P_{H_{2}} A * t * p}{l}
$$

Since diffusion through the liner is very limited, hydrogen diffusion rate is not related with the hydrogen concentration in the feed side, until the concentration is higher than the diffusion capability of the material. Diffusion rate depends on the material permeability coefficient, feed gas pressure and liner thickness. However, setting the hydrogen concentration in stored gas (feed side) can show the relative loss of the hydrogen from the entire amount of stored hydrogen.

\section{Results}

After setting the sample in the holder, vacuuming and putting the feed and carrier gas, measurements were done every 2-3 days, followed by the vacuuming and filling the permeate side with carrier gas (helium) after each measurement. Steady state was achieved after several days of exposure on feed gas. Plot, presenting the measured concentrations of hydrogen in time is presented in figure 2.

A stable increase of concentration of hydrogen per day was observed for the first several days, usually up to 2 weeks. After that time there was a slight decrease, followed by the stabilisation of the diffusion ratio. Permeability coefficient of the samples were calculated after achieving steady state diffusion. However, there is a possibility to calculate a diffusion coefficient for shorter periods of storage, which will decrease the hydrogen loss in time unit. 


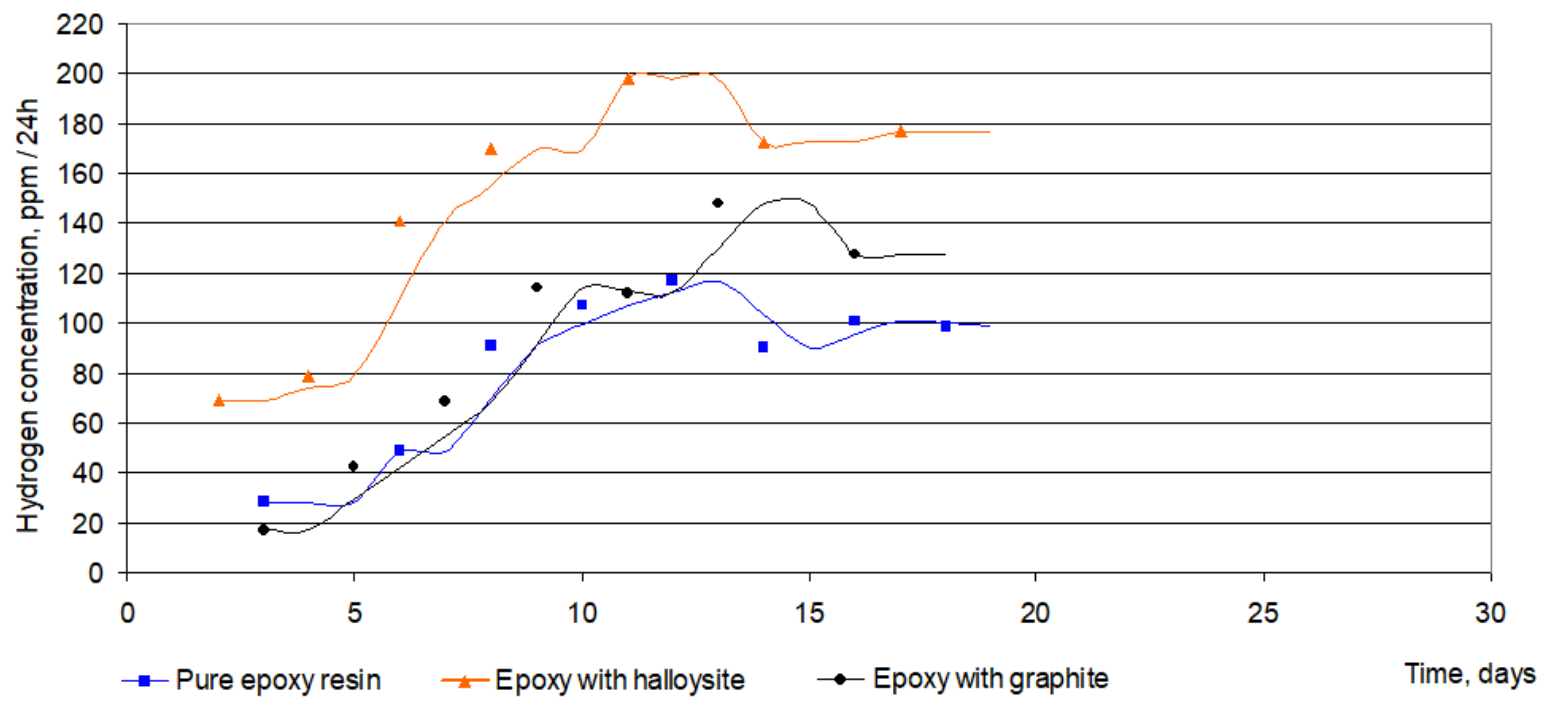

Fig. 2: Concentration of hydrogen in time.

Performed tests of epoxies show the differences in the permeability ratio $\left(\mathrm{P}_{\mathrm{H} 2}\right)$ of the investigated samples. The lowest hydrogen permeability after achieving the steady state, was measured in the pure sample, made from the epoxy resin. The value of hydrogen permeability ratio was 0,185 barrer. Additives, like grinded halloysite are accelerating the hydrogen diffusion process. The same result is caused by the addition of graphite, although the permeability increase was slighter. Permeability ratios of the epoxy resin with halloysite and graphite were 0,316 barrer and 0,238 barrer respectively. Permeability increase in both cases is caused by appearing the voids and contact surfaces between the added grains. Halloysite has a structure of nanotubes with inner diameter of approx. $15 \mathrm{~nm}$. What is more, halloysite consists more than $1 \%$ of hydrogen in its structure, which might accelerate the molecular diffusion. That is why the epoxy with halloysite has the highest permeability ratio among the tested samples. Amorphous graphite also caused the increase of the permeability, but the value was lower than in the halloysite sample. In both cases, additives create another possible way for hydrogen to diffuse, apart from the molecular exchange, which might be the main type of hydrogen diffusion through the pure epoxy resin. Hydrogen permeability ratios of tested samples are shown in the table 1.

A sample of salt rock was also investigated. In this case, test and calculations were performed using Steady-State Flow Method [6], because of the flow of gas through the sample, rather than the diffusion. Flow was identified with the increase of the gas pressure in permeate (downstream) side and drop of the pressure in reservoir. When testing the epoxies, pressure on the permeate side remained stable. Salt sample comes from the high quality Zechstein - Permian deposit. It is a salt dome type of deposit in Poland. Permeability of tested salt is significantly higher than the epoxies, but comparable with general permeability of salt rock. After 12 days of exposure of sample to confining pressure of water $(2,0 \mathrm{MPa})$, salt became impermeable, probably because of salt creep process, occurred in the sample. Gas permeability decreased significantly to the value of 0,195 barrer, comparable to epoxy resin permeability. Storage of hydrogen in investigated salt would be efficient because of much greater thickness of the salt. Gas pressure would also cause the creep process, which will increase the salt sealing properties. 
Table 1: Hydrogen permeability ratios

\begin{tabular}{|l|c|c|}
\hline \multirow{2}{*}{ Sample } & \multicolumn{2}{|c|}{ Permeability coefficient P (hydrogen) } \\
\cline { 2 - 3 } & $\left(\mathrm{cm}^{3} \mathrm{STP}^{*} \mathrm{~cm}^{*} \mathrm{~cm}^{-2} \mathrm{~s}^{-1} \mathrm{cmHg}^{-1}\right)$ & barrer \\
\hline Epoxy resin & $0,185^{*} 10^{-10}$ & 0,185 \\
\hline Epoxy resin with graphite (5\% of volume) & $0,238^{*} 10^{-10}$ & 0,238 \\
\hline Epoxy resin with halloysite (5\% of volume) & $0,316^{*} 10^{-10}$ & 0,316 \\
\hline Salt rock (up to 12 days) & $4,815^{*} 10^{-7}$ & $4,815^{*} 10^{3}$ \\
\hline Salt rock (after 12 days, salt creep process occurred) & $0,195^{*} 10^{-10}$ & 0,195 \\
\hline Stainless steel 316SS [9] & $5,104 * 10^{-17}$ & $5,104 * 10^{-7}$ \\
\hline
\end{tabular}

The permeability coefficient of stainless steel, obtained from performed tests was not reliable, due to the setup sensitivity, in particular small sample diameter and possible additional diffusion through the sleeve or contact surface between sleeve and sample. Permeability of steel is significantly lower (a couple of orders of magnitude) than epoxies. Permeability of stainless steel shown in the table 1 was calculated using the equations form this paper, but basing on the literature data [9]. Example of hydrogen volume, diffusing through the considered lining samples from the theoretical underground storage is presented in the table 2 .

Table 2: Hydrogen loss using different lining materials

\begin{tabular}{|l|l|}
\hline Storage parameters & Value \\
\hline Storage dimensions & Diameter: $7,5 \mathrm{~m}$, height: $100,0 \mathrm{~m}$ \\
\hline Storage volume & $4415,6 \mathrm{~m}^{3}$ \\
\hline Storage inner surface & $2444,5 \mathrm{~m}^{2}\left(24445497 \mathrm{~cm}^{2}\right)$ \\
\hline Storage gas pressure & $10,0 \mathrm{bar}(1,0 \mathrm{MPa})$ \\
\hline Volume of stored gas & $44156,2 \mathrm{~m}^{3} \mathrm{STP}$ \\
\hline Concentration of hydrogen & $20 \%$ \\
\hline Volume of stored hydrogen & $8831,2 \mathrm{~m}^{3} \mathrm{STP}$ \\
\hline Lining thickness & $3 \mathrm{~cm}^{-1}$ \\
\hline Storage time & $30 \mathrm{days}^{-}$ \\
\hline Hydrogen loss during storage time (percentage loss in & brackets $)$ \\
\hline Stainless steel 316SS $[9]$ & $7,98 * 10^{-7} \mathrm{~m}^{3} \mathrm{STP}$ \\
\hline Epoxy & $0,28 \mathrm{~m}^{3} \mathrm{STP}\left(\mathrm{H}_{2}: 0,003 \%\right)$ \\
\hline Epoxy with graphite & $0,37 \mathrm{~m}^{3} \mathrm{STP}\left(\mathrm{H}_{2}: 0,004 \%\right)$ \\
\hline Epoxy with halloysite & $0,49 \mathrm{~m}^{3} \mathrm{STP}\left(\mathrm{H}_{2}: 0,006 \%\right)$ \\
\hline Salt rock (before salt creep) & $7634,1 \mathrm{~m}^{3} \mathrm{STP}\left(\mathrm{H}_{2}: 86 \%\right.$, total gas: $\left.17 \%\right)$ \\
\hline Salt rock (after salt creep) & $0,31 \mathrm{~m}^{3}\left(\mathrm{H}_{2}: 0,003 \%\right)$ \\
\hline
\end{tabular}


According to the results shown in table 1 , amount of $1,8^{*} 10^{-11}$ to $3,1 * 10^{-11} \mathrm{~cm}^{3} \mathrm{STP}$ of hydrogen will diffuse through the area of $1 \mathrm{~cm}^{2}, 1 \mathrm{~cm}$ thick material with gas pressure of $1 \mathrm{cmHg}(0,013 \mathrm{bar})$ in every second. These amounts can be easily connected with the theoretical underground storage parameters, including surface area, thickness of the lining, gas pressure and storage time. Thus, the theoretical hydrogen loss in time can be calculated. Comparison of hydrogen loss in certain storage conditions is shown in table 2.

There is one important issue with the exponent of the permeability coefficient. Permeability coefficients of epoxies presented in table 1 are shown as $\left(\mathrm{cm}^{3} \mathrm{STP}^{*} \mathrm{~cm}^{*} \mathrm{~cm}^{-2} * \mathrm{~s}^{-1} * \mathrm{cmHg}^{-1}\right) * 10^{-10}$, which means that the actual values are barrer. The barrer unit has the exponent of $10^{-10}$ included, but it is not included in the equation. Order of magniture is only a result of calculations, which should not have been omitted. In some papers, the $10^{-10}$ exponent is missing and permeability coefficient value is shown as $\left(\mathrm{cm}^{3} S T P * \mathrm{~cm} / \mathrm{cm}^{2}{ }^{*} \mathrm{~s}^{*} \mathrm{cmHg}\right)$. Basing on this example, permeation through $1 \mathrm{~cm}^{3}$ and $1 \mathrm{~cm}$ thick lining in the pressure of 1 bar $(75 \mathrm{cmHg})$ would be $75 \mathrm{~cm}^{3} \mathrm{STP}$ of gas per second, which is obviously a mistake. Data of that kind were presented in [10], where the permeability coefficient was right, however the exponent was missing. Described mistake found in literature, with additional explanation and comparison with proper values, are shown in the table 3.

Table 3: Gas permeability ratios with correct and incorrect exponent from literature

\begin{tabular}{|c|c|c|}
\hline Sample (gas) & Epoxy (hydrogen) & HDPE (nitrogen) \\
\hline Reference & Correct [7] & Incorrect [10] \\
\hline $\begin{array}{l}\text { Permeability coefficient } \mathrm{P} \\
\text { from literature }\end{array}$ & $\begin{array}{c}1,07 \\
\left(\mathrm{~cm}^{3} \mathrm{STP}^{*} \mathrm{~cm}^{*} \mathrm{~cm}^{-2} * \mathrm{~s}^{-1} * \mathrm{cmHg}^{-1}\right)^{*} 10^{-10}\end{array}$ & $\begin{array}{c}2,7 \\
\left(\mathrm{ml} * \mathrm{~mm}^{*} \mathrm{~cm}^{-2 *} \mathrm{~s}^{-1 *} \mathrm{cmHg}^{-1}\right) \\
\text { which leads to: } \\
0,27 \\
\left(\mathrm{~cm}^{3} \mathrm{STP} * \mathrm{~cm}^{*} \mathrm{~cm}^{-2} * \mathrm{~s}^{-1} * \mathrm{cmHg}^{-1}\right)\end{array}$ \\
\hline $\begin{array}{l}\text { Calculated flux } \\
\left(1 \mathrm{~cm}^{2}, 1 \mathrm{~cm} \text { thick, } 1 \text { bar }\right)\end{array}$ & $8 * 10^{-9} \mathrm{~cm}^{3} \mathrm{STP} / \mathrm{second}$ & $20,3 \mathrm{~cm}^{3} \mathrm{STP} /$ second \\
\hline Exponent & Exponent correct & Missing $10^{-10}$ \\
\hline $\begin{array}{l}\text { Correct permeability } \\
\text { coefficient Q }\end{array}$ & As above & $\begin{array}{c}0,27 \\
\left(\mathrm{~cm}^{3} \mathrm{STP}^{*} \mathrm{~cm}^{*} \mathrm{~cm}^{-2} * \mathrm{~s}^{-1} \mathrm{cmHg}^{-1}\right) * 10^{-10}\end{array}$ \\
\hline $\begin{array}{l}\text { Calculated correct flux } \\
\left(1 \mathrm{~cm}^{2}, 1 \mathrm{~cm} \text { thick, } 1 \mathrm{bar}\right)\end{array}$ & As above & $2 * 10^{-9} \mathrm{~cm}^{3} \mathrm{STP} / \mathrm{second}$ \\
\hline
\end{tabular}

\section{Conclusion}

Hydrogen permeability of investigated epoxy resin is very promising. Permeability value for the hydrogen is slightly lower than literature reports for epoxies [7]. High epoxide number of investigated epoxy resin could influence on the lower hydrogen permeability ratio. However, the comparable order of magnitude confirms the proper operation of the setup and performed calculations. Fillings added into the resin are increasing the permeability of hydrogen.

Epoxy resins seem to be promising sealing material for hydrogen storage. Even a thin layer can effectively prevent the hydrogen from diffusing, even in long storage period. Although the hydrogen permeability of epoxy resin is higher than stainless steel, there is still a trace amount of hydrogen diffusing through the epoxies. What is more, density of epoxy resin is much lower than steel, which will not overload the general construction of the tank, even with a thicker layer. Investigated epoxy resin also has a strong adhesive properties. Liquid epoxy resin during the pot time is able to penetrate 
through the shaft lining, fill the voids and reinforce the construction. There is also a good adhesion of epoxy resin with all kind of materials, including steel. That could be helpful during installation of the necessary equipment and inlets of the tank.

\section{Acknowledgements}

Publication supported by Own Scholarship Fund of the Silesian University of Technology in year 2019/2020, grant number: 19/FSW18/0003-03/2019.

\section{References}

[1] D. Gajda, "Podziemne magazynowanie energii jako szansa na rozwoj energetyki odnawialnej”, Etyka Biznesu $i$ Zrown. Rozw - Interdysc. Stud. Teoret.-Empir., no. 4/2018, pp. 19-30, 2018.

[2] L. Vergani, C. Colombo, G. Gobbi, F.M. Bolzoni and G. Fumagalli, "Hydrogen Effect on Fatigue Behavior of a Quenched\&tempered Steel," Proc. Engineer., vol. 74, pp. 468-471, 2014.

[3] A. Kidybinski, "Geotechnical aspects of adapting openings of a closed coal mine into underground gas storage facility (UGSF)", Research Rep. Mining Environm., no. 2/2004, pp. 37-63, 2018.

[4] P. Tengborg, J. Johansson and J.G. Durup, "Storage of highly compressed gases in underground Lined Rock Caverns - More than 10 years of experience", in Proceedings of the World Tunnel Congress 2014 - Tunnels for a better life, Foz do Iguacu, Brasil, 2014, pp. 1-7.

[5] C. R. Matos, J.F. Carneiro and P.P. Silva, "Overview of large-scale underground energy storage technologies for integration of renewable energies and criteria for reservoir identification", J. of Ener. Stor., vol. 21, pp. 241-258, 2019.

[6] D. Gajda, S. Liu and M. Lutyński, "The concept of hydrogen-methane blends storage in underground mine excavations - gas permeability of concrete," in XVI Intern. Forum-Contest of Students and Young Researchers: Topical Issues of Rational Use of Natural Resources - Scientific Conf. Abstracts, St. Petersburg, Russia, 2019, vol. 1 , pp. 348-349

[7] A. S. Maxwell and S.J. Roberts, Review of Data on Gas Migration through Polymer Encapsulants. Oxfordshire, U.K.: Serco Ltd., 2008.

[8] M. B. Hagg, "Gas Permeation Unit (GPU)" in Encyclopedia of Membranes, E. Drioli, L. Giorno, Ed., Berlin Heidelberg: Springer-Verlag, 2015.

[9] C.H. Henager, "Hydrogen Permeation Barrier Coatings," in Materials for the Hydrogen Economy, R.H. Jones, G.J. Thomas, Ed. CRC Press, 2007, pp. 181-190.

[10] S. Zeman and L. Kubik, "Permeability of Polymeric Packaging Materials" Techn. Sc., no. 10/2007, pp. $26-34,2007$. 